\title{
Larval host plant origin modifies the adult oviposition preference of the female European grapevine moth Lobesia botrana
}

\author{
J. Moreau $\cdot$ J. Rahme $\cdot$ B. Benrey $\cdot$ D. Thiery
}

Received: 23 January 2007 /Revised: 8 November 2007 / Accepted: 17 November 2007 /Published online: 8 December 2007

(C) Springer-Verlag 2007

\begin{abstract}
According to the "natal habitat preference induction' (NHPI) hypothesis, phytophagous insect females should prefer to lay their eggs on the host species on which they developed as larvae. We tested whether this hypothesis applies to the breeding behaviour of polyphagous European grapevine moth, Lobesia botrana, an important pest in European vineyards. We previously found that different grape cultivars affect several life history traits of the moth. Because the different cultivars of grapes are suspected to provide different plant quality, we tested the NHPI hypothesis by examining oviposition choice of $L$. botrana among three Vitis vinifera cultivars (Pinot, Chasselas and Chardonnay). In a choice situation, females of L. botrana that had never experienced grapes were able to discriminate between different grape cultivars and preferentially selected Pinot as an oviposition substrate. This 'naive' preference of oviposition could be modified by larval environment: Females raised on grapes as larvae preferred to lay eggs on the cultivar that they had experienced. Furthermore, experience of the host plant during adult emergence could be excluded because when pupae originating from our synthetic
\end{abstract}

\author{
J. Moreau $(\triangle)$ \\ Equipe Ecologie-Evolution, UMR 5561 Biogéosciences, \\ Université de Bourgogne, \\ 6 Bd Gabriel, \\ 21000 Dijon, France \\ e-mail: jerome.moreau@u-bourgogne.fr \\ J. Moreau $\cdot$ J. Rahme $\cdot$ B. Benrey \\ Institut de Zoologie, Université de Neuchâtel, \\ 2007 Neuchâtel, Switzerland \\ D. Thiery \\ UMR INRA ENITAB 1065 Santé Végétale, \\ Institut des Sciences de la Vigne et du Vin, \\ BP 81, 33883 Villenave d'Ornon Cedex, France \\ e-mail: thiery@bordeaux.inra.fr
}

diet were exposed to grapes, the emerging adults did not show preference for the cultivar from which they emerged. The NHPI hypothesis that includes the two sub-hypothesis "Hopkins host selection principle" and "chemical legacy" may thus be relevant in this system.

Keywords Oviposition choice · Grapes · Lobesia botrana . Natal habitat preference induction

\section{Introduction}

One of the major hypotheses in the theory on the evolution of oviposition behaviour is that females select plants that maximise the survival and growth of their progeny (Thompson and Pellmyr 1991). It has been suggested that females may prefer to oviposit on plant species on which they have developed as larvae (Schoonhoven et al. 1998). The adaptive significance of such behaviour is that preference for a host species with comparable features to those in the natal habitat may facilitate quick and efficient dispersal of individuals into a suitable habitat (Davis and Stamps 2004; Stamps and Davis 2006 for a review). An early hypothesis that proposed to explain this phenomenon is known as the Hopkins host selection principle (Hopkins 1917). This hypothesis states that females prefer to lay eggs on the plant species they ate as larvae ("preimaginal conditioning"; Thorpe and Jones 1937). However, despite the long period of time since this hypothesis was proposed, little experimental evidence has emerged to support it (Tabashnik 1985; Thompson and Pellmyr 1991; Kuussaari et al. 2000; Barron 2001; but see Gandolfi et al. 2003 for an exception). Many studies have been criticized for failing to sufficiently isolate the emergent adults from the preimaginal environment (Jaenike 1982, 1988; Barron 2001). 
Thus, either a "chemical legacy" (i.e. traces of behaviourinducing chemical carried through the pupal stage; Corbet 1985) or experience acquired during the early imaginal rather than the pre-imaginal stage could influence the adult response. Indeed, chemical contamination from the larval environment within the pupal cuticle and from the surface of the pupa is difficult to avoid (Barron and Corbet 1999, 2000), even if pupae are isolated from the chemical source before emergence (Van Emden et al. 1996; Poppy et al. 1997) and washed (Cortesero and Monge 1994). A more recent hypothesis has been termed the "neo-Hopkins principle" (Jaenike 1983). It postulates that host preference is determined at the imago stage shortly after emergence from the pupa ("early adult experience", Van Emden et al. 1996; Jaenike 1988; Barron and Corbet 1999).

Results from the above studies support the idea that experience with plant residuals at the larval and/or imaginal stage can influence adult preference. However, in most studies, it has been difficult to identify the specific factors by which larval or pupal experience has changed adult behaviour because several learning mechanisms are involved. Given these difficulties, a more general term to describe situations in which experience with particular stimuli increases subsequent preferences for the same stimuli has been called the "natal habitat preference induction' (NHPI, Davis and Stamps 2004; Stamps and Davis 2006). As emphasized by Stamps and Davis (2006), "NHPI is an umbrella concept that encompasses a number of more specialized terms", such as the Hopkins host selection principle and chemical legacy. In phytophagous insects, the NHPI hypothesis predicts that females prefer to lay their eggs on the same host species on which they developed as larvae.

In this study, we tested the NHPI hypothesis using the European grapevine moth, Lobesia botrana. The polyphagous European grapevine moth, L. botrana (Denis and Schiffermüller) (Lepidoptera: Tortricidae), is an important pest in European vineyards (Roehrich and Boller 1991). Adult females lay single eggs mainly at dusk on grapevine fructiferous organs, either flower buds or developing berries, according to the moth generation in the year, from spring to autumn (Roehrich and Boller 1991). Because larval mobility is almost limited to intra-bunch displacements (Torres-Vila et al. 1997), the plant organ selected on which females oviposit is of primary importance for the larval survival and will condition the individual fitness (Thiéry and Moreau 2005; Moreau et al. 2006a, b). To test the NHPI hypothesis, we conducted choice experiments for females' moths with three grape cultivars. Different cultivars of the host plant were used because they have been shown to be associated with differences in moth reproductive success (Moreau et al. 2006a, b). We therefore assume that the grape cultivars used provide sufficient differences to test the NHPI hypothesis. In this study, we examined the change in oviposition behaviour of adult females according to the plant cultivar from which they had developed as larvae. We also tried to distinguish between pre-imaginal experience, chemical legacy hypothesis and early adult experience by studying the critical stage during which a preference may have developed.

\section{Materials and methods}

\section{Oviposition assays}

Oviposition responses of females were evaluated in a standardized bioassay. The oviposition arena consisted of a large square box $(25 \times 25 \times 25 \mathrm{~cm})$ lined inside with black synthetic felt (Vénilia, Sicope Lda, Portugal) previously washed with hot water before use to remove potential odours. Felt lining was necessary to avoid unexpected oviposition on the arena walls as described in previous work (Gabel and Thiéry 1992; Maher and Thiéry 2004). With this procedure, few eggs were found on the arena walls, and we therefore excluded these from the analysis.

Single gravid females were placed in the box $2 \mathrm{~h}$ before dusk and offered a choice between three cultivars that were centred, parallel to each other, $6 \mathrm{~cm}$ apart on the floor of the arena. The relative positions of bunches were randomised from one cage to another. The grapes (Pinot, Chasselas and Chardonnay) used as substrate for oviposition in the bioassay were provided from the wine-growing station in Auvernier (Canton of Neuchâtel, Switzerland). These bunches were harvested in the morning of the day of the oviposition experiment at a phenology of approximately pea size (Omafra 2003). Three bunches (without leaves) of each cultivar were grouped to offer to each female around 200 unripe berries of each cultivar. These three cultivars naturally growing under geographical area of study and presents rather similar development dynamics. All bunches were similar in size, and we thus excluded differences caused by phenological differences. Bioassays were performed under natural photoperiod in an environmental chamber $\left(22^{\circ} \mathrm{C}, 60 \pm 10 \%\right.$ r.h.). On the following morning (9 A.M.), bunches were collected from the cages, and the eggs were counted directly with a binocular microscope. Number of tested females varied in function of the availability of females and the rate of mating success. Forty replicates were conducted simultaneously and bioassays lasted 5 days.

We conducted three set of experiments (Table 1), and an identical protocol was used for the oviposition choice experiments in each set. The three experiments were designed to analyse the oviposition choice of female reared (1) on grapes as larvae in the field and (2) on diet as larvae 
Table 1 Summary of methods used in the experiments

\begin{tabular}{|c|c|c|c|c|c|c|c|}
\hline & \multicolumn{7}{|c|}{ Experiments: Oviposition choice of females } \\
\hline & \multicolumn{3}{|c|}{ Collected and reared on grape } & \multirow{2}{*}{$\begin{array}{l}\begin{array}{l}\text { Reared on artificial } \\
\text { diet }\end{array} \\
\text { Stock culture }\end{array}$} & \multicolumn{3}{|c|}{$\begin{array}{l}\text { Exposed to grapes as pupae and while } \\
\text { emerging }\end{array}$} \\
\hline Origin of larvae & Field & & & & \multicolumn{3}{|c|}{ Stock culture } \\
\hline Food offered to larvae & Chasselas & Chardonnay & $\begin{array}{l}\text { Pinot } \\
\text { Noir }\end{array}$ & Synthetic diet & \multicolumn{3}{|c|}{ Synthetic diet } \\
\hline Pupae cleaning & $\mathrm{C}$ & $\mathrm{C}$ & $\mathrm{C}$ & $\mathrm{C}$ & $\mathrm{C}$ & $\mathrm{C}$ & $\mathrm{C}$ \\
\hline $\begin{array}{l}\text { Pupae until emergence exposed to host } \\
\text { plant }\end{array}$ & No & No & No & No & Chasselas & Chardonnay & $\begin{array}{l}\text { Pinot } \\
\text { Noir }\end{array}$ \\
\hline Oviposition assays & \multicolumn{7}{|c|}{ Individual mated females exposed to a ternary choice between bunches of the three grape cultivars } \\
\hline
\end{tabular}

C means careful cleaning of the pupae (see text for details)

with no experience of grapes. The third experiment was designed to analyse the effect of an influence of imaginal experience. To do this, larvae fed on artificial diet were exposed as pupae until emergence to bunches of one cultivar.

\section{Mating and oviposition of Lobesia botrana}

Mated females were obtained by assigning each randomly to one male from the same origin. Each couple was placed in a mating chamber (large tube length, $9.5 \mathrm{~cm}$; diameter, $1.5 \mathrm{~cm}$; closed with a damp cotton wool plug) $1-2 \mathrm{~h}$ before dusk. We used newly emerged adults (less than 1-day old). Water was provided ad libitum through a soaked cotton dental wick. Every morning, tubes were screened so that fertilized females initiating egg laying could be selected (in this procedure females stick their eggs on the glass wall), and the selected females were assayed in the evening. To avoid differences in females motivation state (Browne 1993), we standardized female's experience before the experiment by selecting females ovipositing between five and ten eggs during the night before the experiment and 2 days after their confinement with a male. In L. botrana, mating triggers oviposition and unmated females usually do not oviposit except during the few last days of their lifespan when they oviposit unfertile eggs. Our procedure allows us to (1) select mated females that start to oviposit and (2) discard those that have nearly oviposited their complete batch of eggs, as potential fecundity in field females is low (Moreau et al. 2007).

Source and handling of field larvae fed on the grape cultivars

The experiments were conducted on the larvae in the spring (first year generation of L. botrana) and on the adults originating from this larvae from the wine-growing experimental vineyard of Auvernier (Canton of Neuchâtel,
Switzerland), on the following grape cultivars: $V$. vinifera $\mathrm{cv}$ "Chardonnay", "Chasselas" and "Pinot" (Table 1, collected and reared on grape). No insecticide control method was applied to this plot. The fourth and fifth larval instars of $L$. botrana were collected after they nested in young flower buds in June at stage 'end of flowering' (Omafra 2003). This larval instar spent about 4-6 weeks after egg hatching in the experimental vineyard. In this species, aged larvae build nests in the spring, and one nest usually houses one larva. All the larval nests observed were gathered. Larvae were maintained in small polyethylene boxes $(18 \times 12 \times 6 \mathrm{~cm})$ with fresh parts of bunches corresponding to their cultivar of origin. Bunches (without leaves) were harvested from the same site and regularly changed to feed the larvae ad libitum until the end of their development. Larvae were checked daily until pupation, and then pupae were gently removed, cleaned up using a fine brush to eliminate any trace of grape present at the surface of pupae, weighed to the nearest $0.1 \mathrm{mg}$ and placed individually in glass tubes $(70 \times 9 \mathrm{~mm}$ diameter). Tubes were closed with cotton plugs, labelled and stored at $23^{\circ} \mathrm{C}, 60 \pm 10 \%$ r.h. and under natural photoperiod. Adults were sexed immediately at emergence. All newly emerged adults resulting from the grape varieties were used to perform experiments as described above. In total, we harvested 27 mated females reared as larvae from Pinot, 16 from Chasselas and 25 from Chardonnay for the oviposition experiments.

Lobesia botrana reared on artificial diet as larvae with no experience of grapes

The oviposition choice of naïve females was tested using a strain of L. botrana (INRA Bordeaux) originating from individuals collected in a French Sauternes vineyard (cultivar white sauvignon; Table 1, reared on artificial diet). The stock colony has been maintained without diapause for about 20 generations on a semi-artificial diet (see Thiéry and Moreau 2005, for the technical details) at $24 \pm 1^{\circ} \mathrm{C}, 60 \pm$ 
$10 \%$ r.h. with a photoperiod of L15/D8+1 h of dusk. The first 15 photophase hours were at 1,000 lx luminosity and the last one (dusk) at $251 \mathrm{x}$.

To get newly hatched larvae, males and females were placed together in a large cage, and large bands of waxed paper $(20 \times 2 \mathrm{~cm})$ were hung as oviposition support. Oviposition usually begins one night after mating, and once the paper received sufficient number of eggs, it was placed in a plastic box $(18 \times 12 \mathrm{~cm}$; height, $6 \mathrm{~cm})$ for 1 week until the eggs hatched. Eggs were checked daily until hatching. Larvae (age $<24 \mathrm{~h}$ ) were placed on a semi-artificial diet as described in Thiéry and Moreau (2005). Larvae were checked daily until pupation, and the same procedure as described above was applied to these pupae and emerging adults. A total of 23 mated females were tested.

Influence of an imaginal experience: adults exposed to grapes only as pupae and while emerging

To determine if the environment of emerging adults influences oviposition choice, we used the following procedure (Table 1, exposed to grapes as pupae and while emerging). Larvae were reared for their entire development on artificial diet, as described above. Once pupae, they were removed from their food, and all visible pieces of food on their bodies were removed with a fine brush. Pupae were placed in three boxes containing bunches without leaves (i.e. 200-250 unripe berries at a phenology closely after leadshot, Omafra 2003). As a control, we placed some pupae in a box containing the artificial diet. Boxes were checked every morning, and emerging adults were removed, sexed and placed in small tubes when the mating were performed. The same procedure as described above was applied to emerging adults to test the laying preference between the three cultivars. A total of 15 mated females emerging from Pinot, 14 mated females emerging from Chasselas, 15 mated females emerging from Chardonnay and 19 mated females emerging from the artificial diet were tested.

\section{Statistical analysis}

All statistical analyses were conducted using the SPSS 11.5 software for Windows. A Friedman two-way analysis of variance was used to calculate whether there was a significant difference in the choice of oviposition between the three cultivars. Where significant differences between the three foods were found, a non-parametric Wilcoxon signed ranks test was performed to detect which pairs were different.

\section{Results}

Oviposition choice of the females reared on artificial diet

Females reared on the artificial diet with no experience of grapes laid significantly more eggs on Pinot than on the others two cultivars (Table 2, fed as larvae on artificial diet; Fig. 1). Chasselas received fewer eggs than Chardonnay.

Oviposition choice of females collected and reared on grape

Females reared on Pinot as larvae in the wild showed the same laying pattern as females reared on the artificial diet; they laid significantly more eggs on Pinot than on the two others cultivars (Table 2, fed as larvae on Pinot; Fig. 1). Females fed on Chardonnay as larvae laid their eggs preferentially on this cultivar and laid few eggs on Chasselas (Table 2, fed as larvae on Chardonnay; Fig. 1). Chasselas females showed no preference for either cultivar and laid an equivalent number of eggs on them (Table 2, fed as larvae on Chasselas; Fig. 1).

Table 2 Statistical details of oviposition choice of females among the three cultivars (Pinot, Chasselas and Chardonnay) and fed as larvae on entire grapes or on artificial diet and when adults exposed to grapes only as pupae and while emerging

\begin{tabular}{|c|c|c|c|}
\hline \multirow[t]{2}{*}{ Analysis of oviposition choice of L. botrana } & \multirow[t]{2}{*}{ Origin } & \multicolumn{2}{|c|}{ Friedman's test } \\
\hline & & $\chi_{2}^{2}$ & $P$ value \\
\hline \multirow[t]{4}{*}{ Fed on as larvae on: } & Pinot (27) & 14.81 & 0.001 \\
\hline & Chasselas (16) & 4.00 & 0.135 \\
\hline & Chardonnay (25) & 19.67 & 0.0001 \\
\hline & Artificial diet (23) & 33.17 & 0.0001 \\
\hline \multirow[t]{4}{*}{ Adults exposed to grapes as pupae and while emerging } & Pinot (15) & 9.27 & 0.013 \\
\hline & Chasselas (14) & 10.24 & 0.011 \\
\hline & Chardonnay (15) & 8.27 & 0.042 \\
\hline & Artificial diet (19) & 12.27 & 0.001 \\
\hline
\end{tabular}

The numbers in parentheses represent the number of female tested 
Fig. 1 Mean number of eggs laid on grapes on three different cultivars according to the origin of females that were reared as larvae on Pinot, Chasselas, Chardonnay or artificial diet. Pupae were removed from the different types of food. Columns with the same letters are not significantly different $(P>0.05)$ after nonparametric Wilcoxon signed ranks test. NS Non-significant, $* P<0.05, * * P<0.01, * * * P<$ 0.001 (Friedman's test). The number represents the sample size

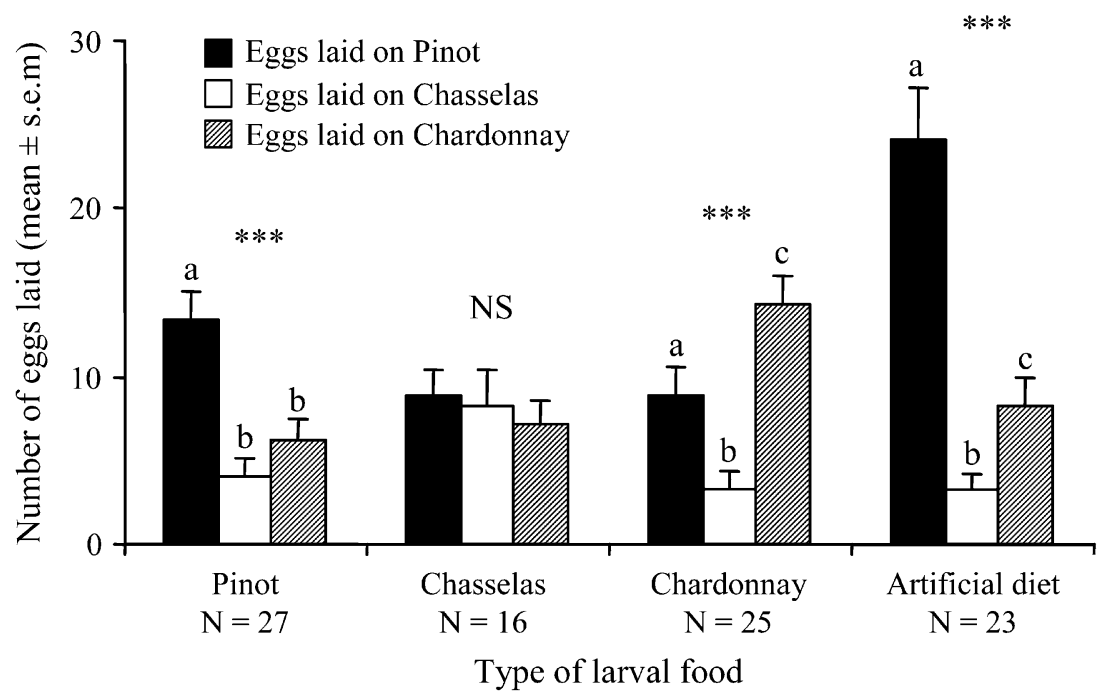

Influence of imaginal experience: oviposition choice of females exposed to grapes only as pupae and while emerging

Larvae that were reared on, and as adults emerged from, the artificial diet laid preferentially more eggs on Pinot, followed by Chardonnay and finally Chasselas being the cultivar that received the least number of eggs (Table 2, adults exposed to grapes as pupae and while emerging; Fig. 2). The same result was observed for females exposed to grapes only as pupae and while emerging larvae: Pinot received more eggs than the two other cultivars (Table 2, adults exposed to grapes as pupae and while emerging; Fig. 2).

\section{Discussion}

Our results confirm previous observations that cultivars are not equally used for oviposition by L. botrana and that females in a choice situation are able to discriminate between grapes of different cultivars (Maher et al. 2001). For females of L. botrana that never experienced grapes, Pinot was preferred as an oviposition substrate compared to the other two cultivars. This is in agreement with recent observations in a multi-cultivar experimental vineyard arranged in small plots with different cultivars. Pinot received the most larvae (33\% of bunches with one or two larvae) as compared to six other cultivars including Chardonnay (16\% of the bunches) and Chasselas (7\%;
Fig. 2 Mean number of eggs laid on grapes on three different cultivars according to the cultivars (or diet) where adults exposed to grapes only as pupae and while emerging and reared as larvae on artificial diet. Columns with the same letters are not significantly different $(P>0.05)$ after non-parametric Wilcoxon signed ranks test. $N S$ Non-significant, $* P<0.05$, $* * P<0.01, * * * P<0.001$ (Friedman's test). The number represents the sample size

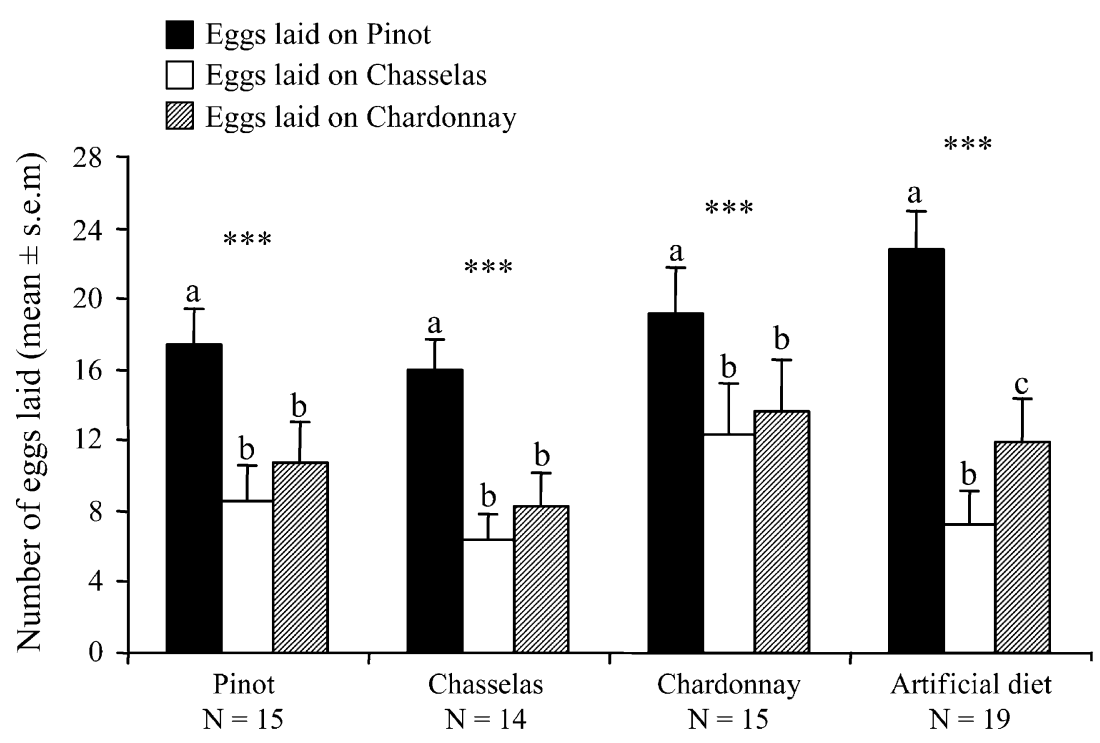

Type of food exposed to pupae + emerging adults 
Thiéry 2008). Chemical and tactile cues likely play a crucial role for ovipositing L. botrana females, and among chemical cues, non-volatile ones seem predominant (Maher and Thiéry 2004; Maher et al. 2006). Previous studies suggest that differential acceptability of grape varieties is mediated by quantitative and/or qualitative variation in oviposition stimulants and deterrents on the plant surface (Maher et al. 2001 and references above). Whatever the mechanisms involved in this choice, the preference of naive females is interesting because previous studies have shown that the Pinot cultivar appears to favour fitness by providing a shorter larval development time than either Chasselas or Chardonnay (Moreau et al. 2006a, b). This finding is consistent with a major working hypothesis on the evolution of oviposition behaviour, which postulates that females will choose plant species that maximize larval survival and growth (Courtney and Kibota 1990; Thompson and Pellmyr 1991; Leather 1994; Janz 2002, but see also Larsson and Ekbom 1995 for a debate and references therein).

Our results show that preference of ovipositing 'naive' females is modified by larval experience of food. This confirms several previous studies using other biological models (i.e. Rietdorf and Steidle 2002, Akhtar and Isman 2003, Anderson et al. 2006, Facknath and Wright 2007). We found that females had an enhanced preference for the host species on which they developed as larvae. Although the Pinot cultivar is more attractive for oviposition than the two other tested cultivars, females originating from Chardonnay preferred to oviposit on their own cultivar. However, females that emerged from Chasselas had no preference for either cultivar. These results do not necessarily indicate that oviposition is not influenced by larval experience but may illustrate a conflict between two forces: the innate strong preference for Pinot being balanced by larval experience on Chasselas. Furthermore, the learned cue was certainly not experienced by the adults during the short period of time after emergence ("early adult experience", Barron and Corbet 1999 and references therein), as females emerging from pupae fed as larvae on artificial diet and placed on grapes did not show preferences for the cultivar from which they emerged. All of these females preferred Pinot, confirming that this cultivar is the most attractive. This result allowed us to reject the phenomenon of "early adult experience" in L. botrana, as the only contact with cultivars experienced by the moths occurred during and after their emergence, and this contact did not modify the oviposition choice made by the females. Therefore, in $L$. botrana, the choice of oviposition species appear to follow the "Hopkins host selection principle" (Hopkins 1917) or the chemical legacy hypothesis (Corbet 1985). However, discerning between the Hopkins host selection principle and the chemical legacy hypothesis may be difficult. This is because the differences could be attributed to the presence, or lack of, tiny amounts of chemicals that may remain inside the pupae or on its surface. Even if larval/pupal material was carefully removed, the presence of a chemical legacy cannot be discarded. This limitation may also apply to several other studies, although very careful attempts to remove chemical information were carried out (Hérard et al. 1988, Van Emden et al. 1996, Barron and Corbet 1999). Traces of the larval diet itself, or for example, as feces, can exist within the body of imago and within the pupal cuticle. It is therefore difficult to ensure that all contaminants from the larval environment are totally removed. Whether the Hopkins host selection principle is involved is difficult to prove in holometabolous insects because the central nervous system is reorganized during the metamorphosis. Despite this, there is accumulating evidence for the retention of operant learning through metamorphosis (Somberg et al. 1970; Isingrini et al. 1985; Tully et al. 1994; Ray 1999).

Although it is difficult to conclude whether the Hopkins host selection principle (Hopkins 1917) or the chemical legacy hypothesis (Corbet 1985) best applies to L. botrana, our results show that an induction of oviposition preference ('NHPI', Davis and Stamps 2004) exists in L. botrana and that it could be observed even by offering experience and choice between different varieties on the same species.

At the same time, our results suggest that the NHPI of $L$. botrana adults by grape cultivars is not very strong, given that females did not lay all their eggs on a single cultivar. Therefore, a polyphagy remains in this species despite this NHPI. Despite the abundance of vineyards across Europe, this insect is still a generalist, with females being attracted to and able to oviposit on alternative plants such as rosemary (Roditakis 1988) or Daphne gnidium (Maher and Thiéry 2006) and larvae completing their development on more than 20 species (Stoeva 1982; Thiéry 2005). The assessment of all life history traits suggests that several of the alternative host plants are of greater nutritional value for larvae or are more phagostimulant than Vitaceae (Thiéry and Moreau 2005). The use of alternative host plants could be maintained in the host range of L. botrana because the fitness of females using alternative host plants is higher than of those raised on Vitaceae.

Despite considerable interest in the effects of NHPI, little attention has been paid to the adaptive significance of this behaviour (Jaenike 1983; Barron 2001, Davis and Stamps 2004, Stamps and Davis 2006). However, the ecological significance of the NHPI may be of interest. The major working hypothesis of the significance of such behaviour is that it might allow adults to locate an oviposition site suitable for larval development more quickly (Davis and Stamps 2004, Stamps and Davis 2006). This statement is mainly true if the insect species is short-lived or has a poor dispersal capacity (as is the case for L. botrana). In the 
specific case of polyphagous grapevine moths, it has been shown that their fitness is influenced by the cultivar upon which they feed, and some cultivars are largely better than others (Thiéry and Moreau 2005; Moreau et al. 2006a, b). Therefore, early inductions of preference could represent a clear advantage if females can select among the cultivars that provide a similar resource to what they have experienced as larvae and thus permit to females to avoid poorer cultivars. It may also be revealing to investigate why NHPI is stronger for females that have experienced Chardonnay as larvae than those that have experienced Chasselas, and whether the NHPI is stronger for females that have experienced a cultivar of good quality as larvae in comparison of those that have experienced cultivar of poorer quality. The ecological significance of the NHPI as reported in this study remains a topic to be investigated.

Acknowledgements This project was funded by the National Centre of Competence in Research (NCCR) Plant Survival, a research programme of the Swiss National Science Foundation. We thank the staff of the wine-growing station of Auvernier (Canton of Neuchâtel, Switzerland) for the free access of vineyard. M.E Toulouse (INRA Bordeaux) is acknowledged for the insect production. We thank Yannick Moret and Clotilde Biard for their helpful comments on the manuscript. We also thank Sarah Overington for checking English in the last version of the manuscript. We certified that experiments comply with the current laws of the countries (Switzerland) in which they were performed.

\section{References}

Akhtar Y, Isman MB (2003) Larval exposure to oviposition deterrents alters subsequent oviposition behavior in generalist Trichoplusia $n i$ and specialist, Plutella xylostella moths. J Chem Ecol 29:1853-1870

Anderson P, Hilker M, Löfqvist J (2006) Larval diet influence on oviposition behaviour in Spodoptera littoralis. Entomol Exp Appl 74:71-82

Barron AB (2001) The life and death of Hopkins' host selection principle. J Insect Behav 14:725-737

Barron AB, Corbet SA (1999) Preimaginal conditioning in Drosophila revisited. Anim Behav 58:621-628

Barron AB, Corbet SA (2000) Behavioural induction in Drosophila: timing and specificity. Entomol Exp Appl 94:159-171

Browne LB (1993) Physiologically induced changes in resourceoriented behavior. Annu Rev Entomol 38:1-25

Corbet SA (1985) Insect chemosensory responses: a chemical legacy hypothesis. Ecol Entomol 10:143-153

Cortesero AM, Monge JP (1994) Influence of pre-emergence experience on response to host and host plant odours in the larval parasitoid Eupelmus vuilleti. Entomol Exp Appl 72:281288

Courtney SP, Kibota TT (1990) Mother doesn't know best: selection of hosts by ovipositing insects. In: Bernays EA (ed) Insect-plant interactions, vol 2. CRC, Boca Raton, FL, USA, pp 161-188

Davis JM, Stamps JA (2004) The effect of natal experience on habitat preferences. Trends Ecol Evol 19(8):411-416

Facknath S, Wright DJ (2007) Is host selection in leafminer adults influenced by pre-imaginal or early adult experience. J Appl Entomol 131(8):505-512
Gabel B, Thiéry D (1992) Biological evidence of an oviposition deterring pheromone in Lobesia botrana (Lepidoptera: Tortricidae). J Chem Ecol 18:353-358

Gandolfi M, Mattiacci L, Dorn S (2003) Preimaginal learning determine adult response to chemical stimuli in a parasitic wasp. Proc Roy Soc Lond B 270:2623-2629

Hérard F, Keller MA, Lewis WJ, Tumlinson JH (1988) Beneficial arthropod behavior mediated by airborne semiochemicals. IV: influence of host diet on host-oriented flight chamber responses of Microplitis demolitor Wilkinson. J Chem Ecol 14:1597-1606

Hopkins AD (1917) A discussion of C.G. Hewitt's paper on "Insect Behaviour". J Econ Entomol 10:92-93

Isingrini M, Lenoir A, Jaisson P (1985) Preimaginal learning as a basis of colony-brood recognition in the ant Cataglyphis cursor. Proc Natl Acad Sci U S A 82:8545-8547

Jaenike J (1982) Environmental modification of oviposition behavior in Drosophila. Am Nat 119:784-802

Jaenike J (1983) Induction of host preference in Drosophila melanogaster. Oecologia 58:320-325

Jaenike J (1988) Effects of early adult experience on host selection in insects: some experimental and theoretical results. J Insect Behav $1: 3-15$

Janz N (2002) Evolutionary ecology of oviposition strategies. In: Hilker M, Meiners T (eds) Chemoecology of insect eggs and egg deposition. Blackwell, Oxford, pp 349-376

Kuussaari M, Singer M, Hanski I (2000) Local specialization and landscape-level influence on host use in an herbivorous insect. Ecology 81:2177-2187

Larsson S, Ekbom B (1995) Oviposition mistakes in herbivorous insects: confusion or a step towards a new host plant? Oikos $72: 155-160$

Leather SR (1994) Life history traits of insect herbivores in relation to host quality. In: Bernays EA (ed) Insect-plant interactions, vol 5. CRC, Boca Raton, FL, USA, pp 175-207

Maher N, Thiéry D (2004) A bioassay to evaluate the activity of chemical stimuli from grape berries on the oviposition of Lobesia botrana (Lepidoptera: Tortricidae). Bull Entomol Res 94:27-33

Maher N, Thiéry D (2006) Daphne gnidium, a possible native host plant of the European grapevine moth Lobesia botrana, stimulates its oviposition. Is a host shift relevant? Chemoecology 16:135-144

Maher N, Jolivet M, Thiéry D (2001) Préférence de ponte de l'eudémis, Lobesia botrana (Lépidoptère, Tortricidae) entre différents cépages de vigne: influence de l'information chimique à la surface des baies. IOBC/WPRS Bull 24(7):103-108

Maher N, Thiéry D, Städler E (2006) Oviposition by Lobesia botrana is stimulated by sugars detected by contact chemoreceptors. Physiol Entomol 31:14-22

Moreau J, Benrey B, Thiéry D (2006a) Grape variety affects larval performance and also female reproductive performance of the European Grapevine moth (Lobesia botrana). Bull Entomol Res 96:205-212

Moreau J, Benrey B, Thiéry D (2006b) Assessing larval food quality for phytophagous insects: are facts as simple as it appears? Funct Ecol 20(4):592-600

Moreau J, Thiéry D, Troussard JP, Benrey B (2007) Grape variety affects female but also male reproductive success in wild European grapevine moths. Ecol Entomol 32:747-753

OMAFRA Staff (2003) Growth stages of grapevine, Ministry of Agriculture, food and rural affairs, Ontario. http://www.omafra. gov.on.ca/english/crops/facts/grapestages.htm

Poppy GM, Powell W, Pennacchio F (1997) Aphid parasitoid responses to semiochemicals-genetic, conditioned or learnt? Entomophaga 42:193-199

Ray S (1999) Survival of olfactory memory through metamorphosis in the fly Musca domestica. Neurosci Lett 259:37-40 
Rietdorf K, Steidle JLM (2002) Was Hopkins right? Influence of larval and early adult experience on the olfactory response in the granary weevil Sitophilus granarius (Coleoptera, Curculionidae). Physiol Entomol 27:223-227

Roditakis NE (1988) Factors affecting population size of grapes berry moth Lobesia botrana Den. \& Schiff. in Crete. In: Cavalloro R (ed) Influence of environmental factors on the control of grape pests diseases and weeds. ECC, Balkema Amsterdam, pp 69-76

Roehrich R, Boller E (1991) Tortricids in vineyards. In: Van der Gesst LPS, Evenhuis HH (eds) Tortricid pests: their biology, natural enemies and control. Elsevier, Amsterdam, pp 507-514

Schoonhoven LM, Jerny T, Van Loon JJA (1998) Insect-plant biology: from physiology to evolution. Chapman and Hall, London

Somberg JC, Happ GM, Schneider AM (1970) Retention of a conditioned avoidance response after metamorphosis in mealworms. Nature 228:87-88

Stamps JA, Davis JM (2006) Adaptative effects of natal experience on habitat selection by dispersers. Anim Behav 72:1279-1289

Stoeva R (1982) Les hôtes de la teigne bariolée des vignes Lobesia botrana Schiff en Bulgarie. Hort Vitic Sci 19:83-89

Tabashnik BE (1985) Deterrence of diamondback moth (Lepidoptera: Plutellidae) oviposition by plant compounds. Environ Entomol 14:575-578
Thiéry D (2005) Vers de la grappe, les connaître pour s'en protéger. Vigne et Vin, Bordeaux, France

Thiéry D (2008) Les tordeuses nuisibles aux vignobles. In: Kreiter S (ed) Les ravageurs de la vigne, 2nd edn. Féret publication, Bordeaux, France (in press)

Thiéry D, Moreau J (2005) Relative performance of European grapevine moth (Lobesia botrana) on grapes and other hosts. Oecologia 143:548-557

Thompson JN, Pellmyr O (1991) Evolution of oviposition behavior and host preferences in Lepidoptera. Ann Rev Entomol 36: 65-89

Thorpe WH, Jones FGW (1937) Olfactory conditioning in a parasitic insect and its relation to the problem of host selection. Proc Roy Soc Lond B 124:56-81

Torres-Vila LM, Stockel J, Roehrich R, Rodriguez-Molina MC (1997) The relation between dispersal and survival of Lobesia botrana larvae and their density in vine inflorescences. Entomol Exp Appl 84:109-114

Tully T, Preat T, Boynton SC, Del Vecchio M (1994) Genetic dissection of consolidated memory in Drosophila. Cell 79:35-47

Van Emden HF, Sponagl B, Wagner E, Baker T, Ganguly S, Douloumpaka S (1996) Hopkins' "host selection principle", another nail in its coffin. Physiol Entomol 21:325-328 